\title{
TOUCH INTERACTION WITH 3D GEOGRAPHICAL VISUALIZATION ON WEB: SELECTED TECHNOLOGICAL AND USER ISSUES
}

\author{
L. Herman ${ }^{\text {a, * }}$, Z. Stachoň ${ }^{\text {a }}$, R. Stuchlík ${ }^{\text {a }}$, J. Hladík ${ }^{\text {a }}$, P. Kubíček ${ }^{\text {a }}$ \\ ${ }^{a}$ Department of Geography, Faculty of Science, Masaryk University, Kotlářská 2, 61137 Brno, The Czech Republic - \\ herman.lu@mail.muni.cz, zstachon@geogr.muni.cz, radim.stuchlik@mail.muni.cz, hladikjiri@mail.muni.cz, \\ kubicek@geogr.muni.cz
}

Commission VI, WG VI/4

KEY WORDS: 3D visualization, interaction, human computer interaction, user issues, touch screen.

\begin{abstract}
:
The use of both 3D visualization and devices with touch displays is increasing. In this paper, we focused on the Web technologies for 3D visualization of spatial data and its interaction via touch screen gestures. At the first stage, we compared the support of touch interaction in selected JavaScript libraries on different hardware (desktop PCs with touch screens, tablets, and smartphones) and software platforms. Afterward, we realized simple empiric test (within-subject design, 6 participants, 2 simple tasks, LCD touch monitor Acer and digital terrain models as stimuli) focusing on the ability of users to solve simple spatial tasks via touch screens. An in-house testing web tool was developed and used based on JavaScript, PHP, and X3DOM languages and Hammer.js libraries. The correctness of answers, speed of users' performances, used gestures, and a simple gesture metric was recorded and analysed. Preliminary results revealed that the pan gesture is most frequently used by test participants and it is also supported by the majority of 3D libraries. Possible gesture metrics and future developments including the interpersonal differences are discussed in the conclusion.
\end{abstract}

\section{INTRODUCTION}

The use of 3D visualization of spatial data is becoming very important in many fields and with regard to different particular tasks. Applications like Google Earth or Virtual Earth have generated a considerable expansion of the third dimension in the geoinformatics domain and geography. The use of 3D visualization in areas of emergency planning, crisis management, noise mapping, urban planning, geographical education or virtual tourism is growing (Biljecki et al., 2015; Lin et al., 2015; Svatonova and Rybansky, 2014; Herman and Reznik, 2013; Popelka and Brychtova, 2013; Bandrova et al., 2012; Konecny and Stanek, 2010).

Wood et al. (2005) present that most 3D geovisualization approaches are technology driven rather than theory driven. Some authors, e. g. Vozenilek (2005), argued that 3D visualization is capable of presenting a large amount of complex information to wider audiences, including those with little or no cartographic literacy. But only few scientific studies has been focused on the confirmation or the refutation of this statement. The exceptions are, for example, studies from Sprinarova (2015), Wilkening and Fabrikant (2013) or Bleisch et al. (2008). The existing empirical studies on 3D visualizations and the different conceptual aspects were analysed by Lokka and Coltekin (2016) and Coltekin et al (2016) explicitly naming tasks, stimuli, and users as the key factors. Both papers stressed the necessity to conduct further empirical studies in order to understand the specific usefulness and usability of 3D visualizations. Therefore we decided to in analysing both the technological (interaction is a part of stimuli) and the user aspects of interaction with 3D models using the touch screen in this paper.
Our study focuses on the usability of touch displays; hence they are widely used in various devices from cell phones to large computer displays.

Based on the increasing number of existing 3D visualizations of spatial data we have established the following research question:

- Are different technologies ready for visualization and interactive control of $3 \mathrm{D}$ visualization?

- Are there universal gestures for controlling 3D virtual geographic environment?

- What are the available metrics for gesture measurements and how they differ on the level of individual users?

In the next part of the article, we will present the literature and technology review and the particular pilot usability study focused on the verification of the means of interaction enabled through various web technologies and hardware devices.

\section{RELATED RESEARCH}

The user aspects of interactive $3 \mathrm{D}$ visualization is an issue that has been mentioned by several authors (Lokka and Coltekin 2016, Herman and Stachon, 2016; Wilkening and Fabrikant, 2014; Popelka and Brychtova, 2013; Bleisch et al., 2008), but relatively little is known about effective use of interactive $3 \mathrm{D}$ visualizations. For this reason, we focused on the interactive 3D visualization and on its interaction with spatial data via touch screens.

Controlling the interactive 3D visualization can be based on different principles and technologies. Canare et al. (2015) refer to the mouse-driven design of most of the contemporary applications. The common desktop computer interface is controlled by a computer mouse, which offers two degrees of

\footnotetext{
* Corresponding author
} 
freedom (DoF). A different way of interaction constitutes touch displays, which provides also two degrees of freedom.

Empirical testing of $3 \mathrm{D}$ interactive virtual environments is relatively scarce and only limited true results are available. One of the few articles describing such environment is represented by Wilkening and Fabrikant (2014). They used the Google Earth application and monitored the proportion of applied movement types - zoom, pan, tilt, and rotation. Bleisch et al. (2008) assessed the 3D visualization of abstract numeric data. Speed and accuracy were measured, but the information about the navigation in 3D space was not recorded in this study. Sprinarova et al. (2015) compared qualitatively two different types of interaction (PC mouse and Wii Remote Controller) with 3D terrain models. Zhang and Moore (2013) presented an exploratory comparison of work made with three types of software for 3D modelling (CAD, GIS, and virtual environment).

Touch screens and their particular interaction present another view point to take into account. White (2009) considered touch screens particularly as an interesting solution for pointing, as they unite the input to the display to produce a more congruent metaphor to real-world interaction. We can also give some examples of research studies that dealt with the interaction of spatial data. Rönneberg et al (2014) described the development of an in-house experimental application supporting the multitouch interaction with interactive maps. Also, Von Zadow et al. (2011) dealt with an interactive zoom able map. The proposed multi-touch system is called a GeoLens. It was evaluated by the observation of 150 users of this system and the authors consider it as suitable for less experienced users. Jokisch et al (2011) studied the work made with touch screen, depending on the age of the participants of the experiment. They tried to identify the most intuitive gestures when working with a variant of Google Earth. As most intuitive gesture they consider rotation with the 3D model by moving one finger on the touch screen. Marchal et al. (2013) focuses on designing an intuitive system of multitouch techniques for interaction with 3D spatial data. They proposed the system of touch and multi-touch gestures, which was called Move\&Look. The participants in this study compared this system with other techniques. Nurminen and Oulasvirta (2008) and Jankowski et al. (2014) dealt with interaction via touch screens of mobile devices. Daiber (2011) presented another specific type of touch interaction. His study is focused on the interaction with stereoscopically depicted spatial $3 \mathrm{D}$ data.

The possibilities of web-based technologies have not been investigated in any of the mentioned studies. Therefore we decided to concentrate on web based libraries for 3D visualization and touch interaction from the point of view of usability research. We want to measure and analyze the interaction and movement in a virtual environment, because the role of these characteristics is not well known (see above). We want to explore the interaction through touch screens also in term of possible individual differences (based on personality characteristics or previous experiences with 3D visualization or touch screens).

\section{RELEVANT TECHNOLOGIES}

\subsection{Web Technologies for Touch Interaction}

Touch screen devices prevail in the mobile platform. Most of the smartphones and tablets have it; touch screens are becoming common in use for desktop computers as well. There are two ways to create a touch support application - native or using the technologies for web development (HTML, CSS, Javascript). We focused on development via web technologies.

To develop a touch screen that is compatible with web applications, where existing touch events of the browsers are usually used. There are several libraries in JavaScript language that expand these options. Hammer.js is an open-source library that can recognize gestures made by touch, mouse, and pointerEvents. Hammer.js is a jQuery-like API (Application Programming Interface). Quo.js is a modular and objectoriented library for mobile web development. These two libraries are standalone (other similar are e.g. thumbs.js or Jester). Some other libraries for touch events need JQuery, for example Touchy jGestures, jQuery doubletap, Touchable, jQuery.pep.js or Touch Swipe. There are also libraries like Mootools Mobile, which need its own core library (in this case MooTools Core). MooTools is intended for mobile devices with iOS and Android system. Implementation of individual gestures in the mentioned libraries is presented in Tab. 1.

\begin{tabular}{|c|c|c|c|c|c|c|c|c|}
\hline & \multicolumn{8}{|c|}{ Supported gestures } \\
\hline & శ్ & $\begin{array}{l}\text { चे } \\
\text { 0 } \\
0 \\
0 \\
0\end{array}$ & $\begin{array}{l}\tilde{\omega} \\
\tilde{D} \\
\tilde{D}\end{array}$ & 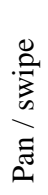 & 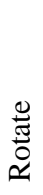 & $\begin{array}{l}\Xi \\
0 \\
0 \\
N \\
\frac{0}{0} \\
\Xi \\
0\end{array}$ & $\stackrel{0}{\tilde{0}}$ & 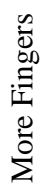 \\
\hline Hammer.js & $\mathrm{x}$ & $\mathrm{x}$ & $\mathrm{x}$ & $\mathrm{x}$ & $\mathrm{x}$ & $\mathrm{x}$ & $\mathrm{x}$ & \\
\hline jGestures & $\mathrm{x}$ & & & $\mathrm{x}$ & $\mathrm{x}$ & $\mathrm{x}$ & & $\mathrm{x}$ \\
\hline $\begin{array}{l}\text { jQuery } \\
\text { doubletap }\end{array}$ & $\mathrm{x}$ & $\mathrm{x}$ & & $\mathrm{x}$ & & & & \\
\hline jQuery.pep.js & & & & & & & $\mathrm{x}$ & \\
\hline $\begin{array}{l}\text { Mootools } \\
\text { Mobile } \\
\end{array}$ & & & $\mathrm{x}$ & $\mathrm{x}$ & & $\mathrm{x}$ & & \\
\hline Quo.js & $\mathrm{x}$ & $\mathrm{x}$ & $\mathrm{x}$ & $\mathrm{x}$ & $\mathrm{x}$ & $\mathrm{x}$ & $\mathrm{x}$ & $\mathrm{x}$ \\
\hline \multicolumn{9}{|l|}{ thumbs.js } \\
\hline Touchable & $\mathrm{x}$ & $\mathrm{x}$ & $\mathrm{x}$ & & & & & \\
\hline Touchy & & & $\mathrm{x}$ & $\mathrm{x}$ & $\mathrm{x}$ & $\mathrm{x}$ & $\mathrm{X}$ & \\
\hline
\end{tabular}

Tab. 1. Implementation of basic gestures in Java Script libraries.

\subsection{Web Technologies for 3D Visualization}

A broad spectrum of technologies is available for rendering 3D models, which run on the client side. In addition to thick clients, which are standalone applications such as Google Earth, there are a number of software libraries for displaying 3D models using a simple web browser. Many of them use plug-ins. 3D models can be displayed in a web environment, for example, using Flash plug-in (11.0 and higher), or Microsoft Silverlight, 3.0 and higher (Behr et al., 2009). Plug-ins are also used for the implementation of the so-called virtual globes, for example, NASA World Wind, which is in the Java language.

Presently preference is given to technologies that are operated without plug-ins. These solutions are usually built on HTML5 and JavaScript library WebGL. One of many examples of libraries based on WebGL is X3DOM, which uses the data structure of the X3D (eXtensible 3D) format. X3DOM can also be defined as the declarative languages for $3 \mathrm{D}$ content on the web. The advantage of this library is its broad support in Web browsers and also on mobile devices. The second example of the declarative technology for a $3 \mathrm{D}$ visualization is XML3D. 
Other WebGL-based libraries similar to X3DOM or XML3D are SceneJS, Three.js and SpiderGL, which uses data in a COLLADA file structure (Di Bennedetto et al., 2011). Further overviews of the web technologies used for the visualization of 3D models are provided by Behr et al. (2009), Lienert et al. (2012) or Herman and Reznik (2015).

\section{DEVICES SUPPORT OF GESTURES}

We tried to compare how various gestures work. Several WebGL-based libraries were used for the testing, which can be used for interactive visualization without plug-ins (SceneJS, Three.js, XML3D, X3DOM and SpiderGL). We focused on libraries for the depiction of the general 3D data: terrain models or simple city models at the levels of detail (Lod) 1 or LoD 2. We omitted technologies for the visualization of virtual globes. We compared interactions through touch gestures with different libraries on different devices (smartphones, tablets and touch screens). The gestures, which have been evaluated, can be classified into two main groups:

- Gestures based on one finger: tap (one-finger short press, lift) press (one-finger press, wait, lift), pan (one-finger press, move, lift) and swipe (similar to a pan, but this recognizer makes an instantaneous decision as to whether the touch moved linearly in the required direction).

- Gestures using two fingers: pinch (two-finger press, move outwards or inwards, lift), rotate (two-finger press, simultaneously orbit both fingers around the central point, lift)

Results from the evaluation of the support of individual gestures are enclosed in the appendix. The pan is the gesture supported in most libraries, being considered as the easiest gesture (shifts of one finger on the screen). Zooming is also relatively well supported. The support for other gestures is significantly differentiated between devices. The role of the operating system also seems to be important.

It was not possible to interact with the library SpiderGL on any device and in any internet browser. Libraries X3DOM and XML3D are the most commonly supported at used devices, both in terms of the depiction of 3D scenes and its interaction with it. We can consider the support of tested technologies on tablets as very problematic. It was not possible to control them or even display the 3D scenes. Testing was also tried for the Lenovo tablet running Windows 8.1, but this did not work with any of the above mentioned technologies.

\section{PILOT EXPERIMENT}

\subsection{Implementation}

Based on the lack of software tools for the usability testing of 3D visualization our own experimental tool has been designed and implemented. This tool is based on open web technologies: HTML (HyperText Markup Language), PHP (Hypertext Preprocessor), JavaScript and JavaScript libraries X3DOM (for 3D interactive visualization) and Hammer.js (for gesture recognition). Principles, advantages, and capabilities of X3DOM are described by Behr et al (2009) or Herman and Reznik (2015).

The testing tool record the following characteristics:

- The speed of user performance (efficiency) shows how quickly the participant can perform a task.

- Answers and their correctness (effectiveness) of users' tasks while using a system. Participants select from multiple answers. HTML checkboxes were used for implementation of the interface for answers.

- The movement in virtual space, which is stored as a list of 3D coordinates of the virtual camera position, vectors of camera orientation and time stamps. Recording and basic analysis of the movement in virtual space are described in detail by Herman and Stachon (2016).

- Used gestures on touch screen were recorded in the testing tool using recognizers defined in Hammer.js library. The following gestures are distinguished: pan, pinch (zoom), press, rotate, swipe and tap. The explanation of these gestures is shown in Fig. 1.

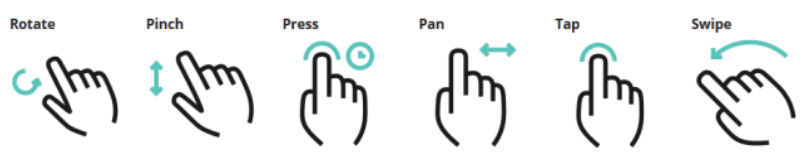

Fig. 1. Gestures detected by Hammer.js library (source: http://hammerjs.github.io).

\subsection{Design, Participants and Stimuli}

The simple within-subject design was chosen due to the fact that it was a pilot experiment. The test battery consists of two parts. The first part was represented by two simple tasks. Both tasks were focused on determination of the visibility of four points from the top of the particular mountain. The second part was a simple questionnaire focusing on the basic demographic data and participants previous experiences. The participants were 6 volunteers - students of the course "3D visualisation and modelling in cartography". There were 3 males and 3 females in the group. All of the participants have a bachelor degree from cartography.

In three cases, users reported that they rarely meet with $3 \mathrm{D}$ visualization (once in a while), in two cases occasionally (about once per week), and in one case frequently (more times a week). Participants that reported meeting with touch-screens very often (five of participants) or often (one participant). Most participants work most often with smartphones, in one case with the tablet and in other case with the smartphone (often) and sometimes also with the notebook with the touch screen. Users also did the self-assessment of their skills in touch interaction. Three participants stated that they are proficient in touch interaction and three participants reported that they do not have significant problems with the interaction.

LCD monitor Acer FT240HQL was used for the pilot experiment. The touch screen has a diagonal size 23.6" $(60 \mathrm{~cm})$ and the experiment has been occurring with resolution $1920 \mathrm{x}$ 1080 pixels. The default views on both the 3D scenes in the pilot experiment are shown in Fig. 2.

Digital terrain models represented the stimulus material used for described experiment. Terrain models from two different areas in Europe acquired by SRTM (Shuttle Radar Topography Mission) were used. These data were processed in ArcGIS 10.2 software. Raster terrain models were transferred to the regularly arranged points then they were transformed into TIN (Triangulated Irregular Network) models. The Universal Transverse Mercator (UTM) coordinate system was used for our purpose. TINs were converted to raster terrain models and then clipped to a smaller size. They have been visualised in ArcScene, base heights as a double of the real altitude and colour scheme were set. Finally, the digital terrain models were exported to the VRML (Virtual Reality Modelling Language) files and converted into an X3D. 
Task 1

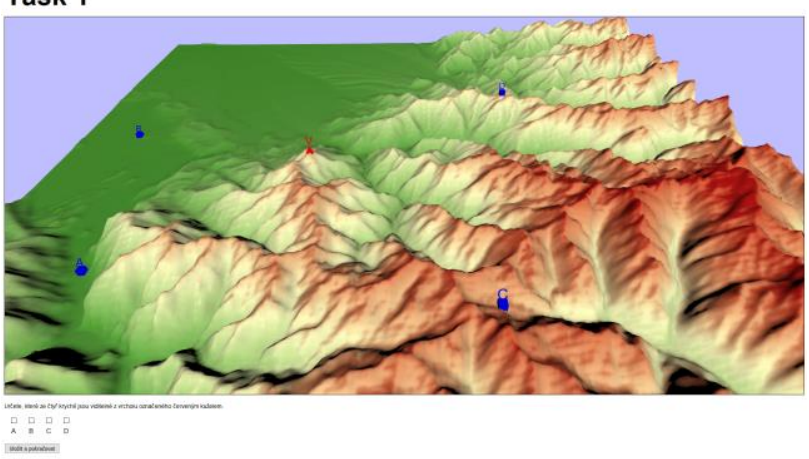

Task 2

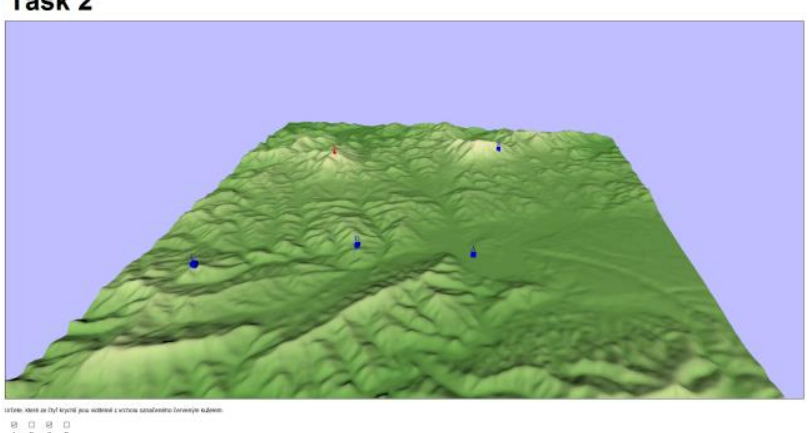

Fig. 2. Screenshots from testing tasks 1 and 2. Assignments: Determine which of the four cubes $(\mathrm{A}-\mathrm{B}-\mathrm{C}-\mathrm{D})$ are visible from the top marked with red cone.

\subsection{Results}

The correctness of answers, duration of tasks (speed of users' performance), distance and speed in a virtual environment and proportion of used gestures were analysed.

The correctness of the answers were $100 \%$ in both tasks. The average speed of users' performance was 27.7 seconds (st. dev. $6.4 \mathrm{~s}$ ) in first task and 26.6 seconds (st. dev. 14.5 s) in the second task. The speed of individual user's performances is shown in Fig. 3. The majority of users solved $2^{\text {nd }}$ task faster than $1^{\text {st }}$ task (see Fig. 3), probably due to the learning effect. The participants were more familiarized with touch interaction and $3 \mathrm{D}$ environment during the $2^{\text {nd }}$ task.

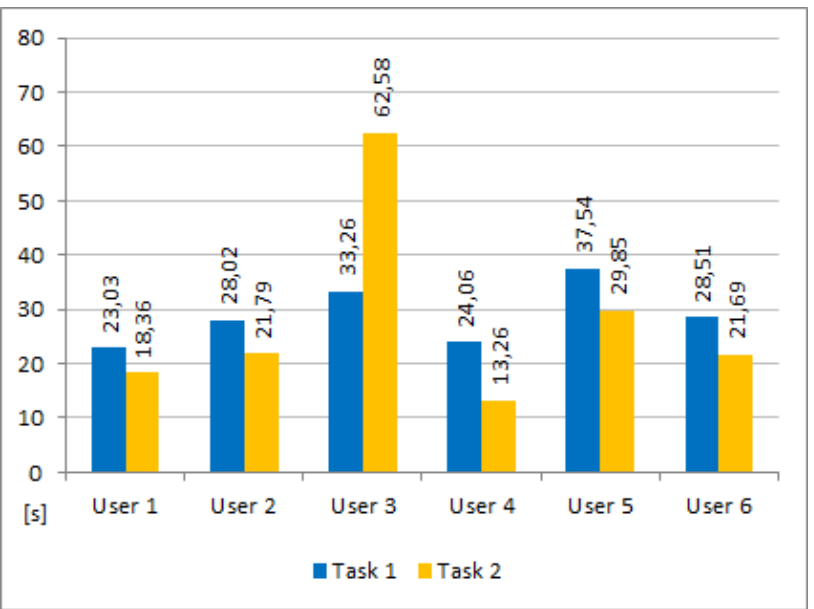

Fig. 3. The speed of task performance (in seconds) for individual users.

If we consider the total time of solving both tasks, the fastest participant was number four (total time $37.32 \mathrm{~s}$ ), which is the only participant stated to sometimes work with a laptop with a touchscreen. So only this participant has experience with touch screen with the larger size system.

A notable exception is participant number three, who addressed the second task much longer than the first one. This participant intensively interacts with the environment all the time and only this participant has a significant usage of gesture press (in both tasks).

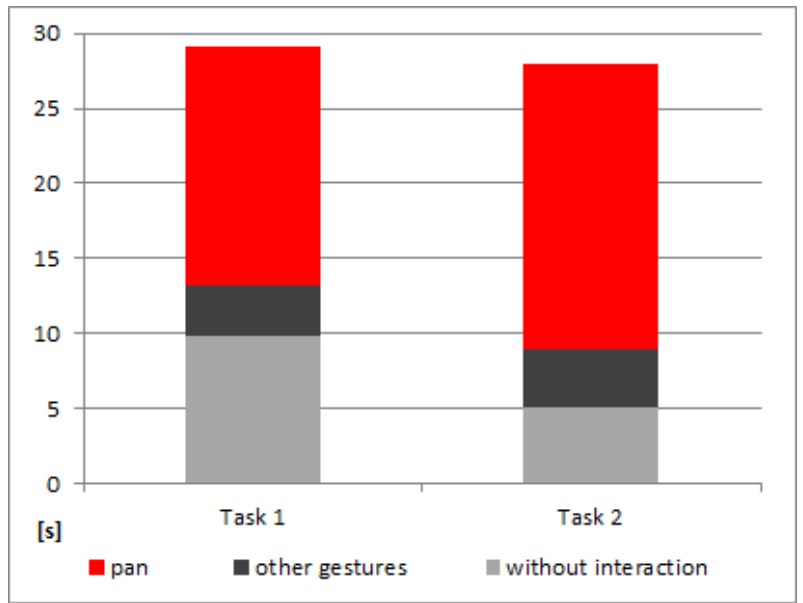

Fig. 4. Average time (in seconds) spent by interaction through gestures.

From a global point of view, if we look at gestures used for interaction with 3D models (see Fig. 4), it is obvious that users use the simplest gesture - pan (move one finger across the screen) most of the time. Other gestures are used less often, but there are relatively big differences between individual participants.

The time between movement and the beginning of tasks solving are relatively similar between participants $\left(1^{\mathrm{st}}\right.$ task: mean $3.93 \mathrm{~s}$, st. dev. $1.23 \mathrm{~s} ; 2^{\text {nd }}$ task: mean $2.67 \mathrm{~s}$, st. dev. $0.43 \mathrm{~s}$ ) and also the time used for answering questions - checking the checkboxes ( $1^{\mathrm{st}}$ task: mean $5.98 \mathrm{~s}$, st. dev. $4.08 \mathrm{~s} ; 2^{\text {nd }}$ task: mean $2.44 \mathrm{~s}$, st. dev. $0.69 \mathrm{~s})$

When we look at the pan gesture in more detail (see Tab. 2), we can observe the proportion of the four basic directions (left, right, top, down) of finger movement on the screen. This kind of data is also monitored in Hammer.js library. Average times spent by panning into individual direction are shown in Fig. 5. The average values of time are relatively balanced between both tasks and also between all four directions. The only exception represents the highest proportion of pan to the right in the second task. 


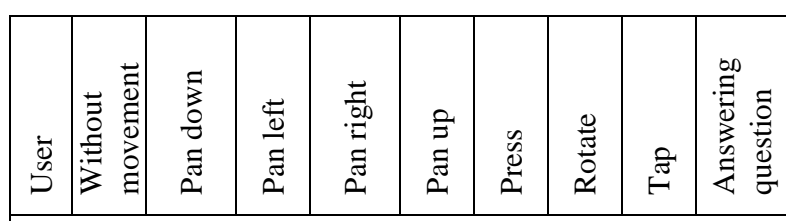

Task 1

\begin{tabular}{|r|r|r|r|r|r|r|r|r|r|}
\hline 1 & 2.80 & 1.84 & 1.57 & 2.38 & 3.82 & 0.10 & 0.00 & 0.00 & 10.52 \\
\hline 2 & 2.84 & 3.70 & 6.03 & 3.34 & 0.88 & 1.64 & 2.37 & 3.08 & 4.14 \\
\hline 3 & 3.55 & 4.21 & 0.01 & 7.76 & 6.35 & 6.15 & 0.00 & 1.64 & 3.59 \\
\hline 4 & 4.05 & 3.00 & 6.73 & 3.65 & 3.74 & 0.95 & 0.25 & 0.00 & 1.69 \\
\hline 5 & 3.89 & 10.20 & 7.65 & 3.90 & 5.90 & 1.43 & 1.16 & 0.14 & 3.27 \\
\hline 6 & 6.46 & 4.70 & 0.70 & 2.31 & 1.02 & 0.67 & 0.00 & 0.00 & 12.65 \\
\hline
\end{tabular}

Task 2

\begin{tabular}{|r|r|r|r|r|r|r|r|r|r|}
\hline 1 & 2.32 & 1.11 & 4.02 & 3.90 & 2.06 & 2.53 & 0.52 & 0.00 & 1.90 \\
\hline 2 & 2.28 & 1.68 & 5.27 & 6.60 & 0.52 & 2.75 & 0.02 & 0.01 & 2.66 \\
\hline 3 & 2.60 & 12.99 & 8.54 & 15.89 & 7.84 & 5.36 & 3.72 & 1.89 & 3.75 \\
\hline 4 & 3.56 & 2.62 & 0.84 & 1.70 & 2.95 & 0.00 & 0.00 & 0.00 & 1.59 \\
\hline 5 & 2.46 & 11.00 & 2.69 & 2.21 & 8.67 & 0.00 & 0.25 & 0.07 & 2.50 \\
\hline 6 & 2.79 & 1.35 & 2.22 & 5.12 & 1.79 & 3.84 & 0.00 & 2.36 & 2.22 \\
\hline
\end{tabular}

Tab. 2. Time spent by individual users by interaction through gestures (in seconds).

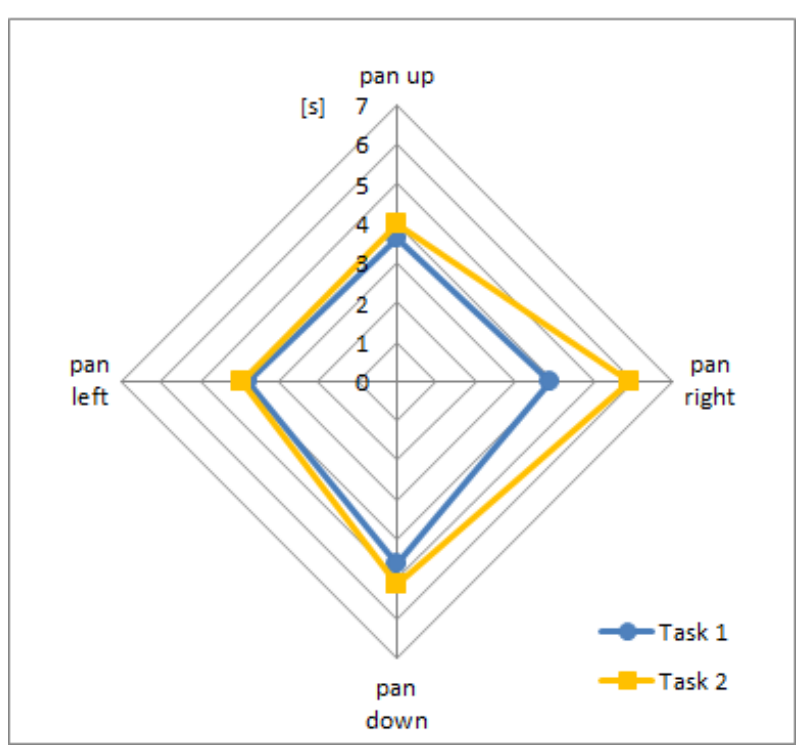

Fig. 5. Average time (in seconds) spent by interaction through pan gesture (divided by direction)

We can deduce a similar conclusion from an analysis of distance traveled in the virtual environment as from the study of individual gestures. The travelled distances and speeds for individual participants are presented in Tab. 3. The average travelled distance was $613.19 \mathrm{~km}$ in the $1^{\text {st }}$ task and $446.47 \mathrm{~km}$ in the $2^{\text {nd }}$ task. The mean speed was $20.41 \mathrm{~km}$ per second in the $1^{\text {st }}$ task and $15.92 \mathrm{~km}$ per second in the $2^{\text {nd }}$ task, but the values of individual participants vary significantly.

\begin{tabular}{|c|c|c|c|c|c|r|}
\hline \multirow{2}{*}{ User } & \multicolumn{3}{|c|}{ Task 1 } & \multicolumn{3}{c|}{ Task 2 } \\
\cline { 2 - 7 } & dist. & time & speed & dist. & time & speed \\
\cline { 2 - 7 } & {$[\mathrm{km}]$} & {$[\mathrm{s}]$} & {$[\mathrm{km} / \mathrm{s}]$} & {$[\mathrm{km}]$} & {$[\mathrm{s}]$} & {$[\mathrm{km} / \mathrm{s}]$} \\
\hline 1 & 378.67 & 23.03 & 16.44 & 251.26 & 18.36 & 13.69 \\
\hline 2 & 653.82 & 28.02 & 23.33 & 179.84 & 21.79 & 8.25 \\
\hline 3 & 534.95 & 33.26 & 16.08 & 1037.50 & 62.58 & 16.58 \\
\hline 4 & 522.50 & 24.06 & 21.72 & 191.93 & 13.26 & 14.47 \\
\hline 5 & 1290.43 & 37.54 & 34.37 & 352.82 & 29,85 & 11.82 \\
\hline 6 & 298.79 & 28.51 & 10,48 & 665.48 & 21.69 & 30.68 \\
\hline
\end{tabular}

Tab. 3. Virtual distances, lengths of user performances and speeds of individual users in task 1 and 2.

\section{CONCLUSIONS}

Based on the increasing support of touch interaction in available web libraries for 3D visualization, we studied the availability and user performance on different hardware (desktop PCs with touch screens, tablets, and smartphones) and software platforms. We can conclude that pan is a gesture of a relatively good support across used devices. Zooming is also relatively well supported. Support for other gestures is significantly smaller and differ between devices.

For the purposes of pilot experiment with web tool based on JavaScript, PHP, X3DOM, and Hammer.js were developed and used. When comparing results from testing of individual 3D libraries and the results of describing the pilot experiment, it is evident that the most commonly used gesture (pan) is also supported in most of the 3D libraries. This result corresponds with the findings made by Jokisch et al. (2011) and Von Zadow et al. (2011). Von Zadow et al. (2011) identified as most usual interaction with one finger. Jokisch et al. (2011) studied using gestures and their intuitivism in larger detail. Participants in similar age as in our study (20 - 30 years) intuitively operate with the multi-touch screen. They used most often panning and zooming and do not have any problem with its usage.

The main advantage of a developed tool is that JavaScript libraries (Hammer.js and X3DOM) allow deeper recording and analysis of pan gesture and an analysis of virtual movement metrics. Pan gesture can further be divided on individual directions (left, right, top, down). Recording of movement in a virtual environment can be transformed for the calculation of virtual speed and travelled direction. Furthermore, the data about movement in the virtual environment can be visualized e.g. as a trajectory above the stimuli (see Herman and Stachon, 2016). A detailed data about user performance in a particular virtual environment allow deeper analysis and proposed visualizations and the derived calculations enable further investigation of the user aspects of interactive $3 \mathrm{D}$ visualization. Therefore, the developed tool can contribute to the ongoing user studies focused on user performance within 3D virtual environments.

Regarding the conceptual aspects of the $3 \mathrm{D}$ visualizations mentioned by Coltekin et al. (2016) we focused primarily on the selected part of the stimuli (interactive visualization using gestures) and other conceptual viewpoints (tasks and users) were homogenous. However, our existing results suggest that the most significant differences can be found particularly among individual participants. This fact may be affected by participant's spatial abilities and previous experience with interacting with $3 \mathrm{D}$ visualization. We can expect a more 
significant difference among users of various age groups, education, professional background etc.

Finally, we can expect an increasing number of devices and applications with the possibility of touch interaction. Therefore we want to focus on the design and realization of much broader experiments with larger numbers of participants in the future.

\section{ACKNOWLEDGEMENTS}

This research was funded by Grant No. MUNI/M/0846/2015, "Influence of cartographic visualization methods on the success of solving practical and educational spatial tasks" and Grant No. MUNI/A/1315/2015, "Integrated research on environmental changes in the landscape sphere of Earth", both awarded by Masaryk University, Czech Republic.

\section{REFERENCES}

Abend P., Thielmann T., Ewerth R., Seiler D., Mühling M., Döring J., Grauer M., Freisleben B. (2012). Geobrowsing behaviour in Google Earth - A semantic video content analysis of on-screen navigation. In: Jekel T. A. et al. (eds.) GI_Forum 2012: Geovisualization, Society and Learning, pp. 2-13.

Bandrova, T., Zlatanova, S., Konecny, M. (2012). ThreeDimensional Maps for Disaster Management. In: Shortis, M., Madden, M. (eds.) ISPRS Annals of the Photogrammetry, Remote Sensing and Spatial Information Sciences, Vol. I-4. Melbourne, Australia, pp. 245-250.

Behr, J., Eschler, P., Jung, Y., Zőllner, M. (2009). X3DOM - A DOM-based HTML5/ X3D Integration Model. In: Proceedings of Web3D 2009: The 14th International Conference on Web3D Technology, Web3D 2011. Darmstadt, Germany.

Biljecki, F., Stoter, J., Ledoux, H., Zlatanova, S., Coltekin, A. (2015). Applications of 3D city models: State of the art review. ISPRS International Journal of Geo-Information, 4(4): 28422889.

Bleisch, S., Dykes, J., Nebiker, S. (2008). Evaluating the Effectiveness of Representing Numeric Information Through Abstract Graphics in 3D Desktop Virtual Environments. Cartographic Journal. 45(3): 216-226.

Canare, D., Chaparro, B., He, J. (2015). A Comparison of GazeBased and Gesture-Based Input for a Point-and-Click Task. In: Antona, M., Stephanidis , C. (eds.) Universal Access in HumanComputer Interaction. Access to Interaction. Switzerland: Springer International Publishing, pp. 15-24.

Coltekin, A., Lokka, I.-E., Zahner, M. (2016). On the usability and usefulness of 3D (geo)visualizations -- A focus on virtual reality environments. In: Halounova, L., et al. (eds.) ISPRS Archives of the Photogrammetry, Remote Sensing and Spatial Information Sciences, Vol. XLI-B2. Prague, Czech Republic.

Daiber, F. (2011). Interaction with Stereoscopic Data on and above Multitouch Surfaces. In: Proceedings of the ACM International Conference on Interactive Tabletops and Surfaces. ACM International Conference on Interactive Tabletops and Surfaces (ITS-11), New York, NY, USA,

Di Benedetto, M., Corsini, M., Scopigno, R. (2011). SpiderGL: A Graphics Library for 3D Web Applications. ISPRS Archives of the Photogrammetry, Remote Sensing and Spatial Information Sciences, Vol. XXXVIII-5/W16, Trento, Italy, pp. 467-474.

Herman, L., Reznik, T. (2013). Web 3D Visualization of Noise Mapping for Extended INSPIRE Buildings Model. In: Hrebicek, J., Schimak, G., Kubasek, M., Rizzoli, A. E. (eds.) Environmental Software Systems. Fostering Information Sharing, Springer, pp. 414-424.

Herman, L., Reznik, T. (2015). 3D Web Visualization of Environmental Information - Integration of Heterogeneous Data Sources when Providing Navigation and Interaction. In Mallet C., et al. (eds.) ISPRS Archives of the Photogrammetry, Remote Sensing and Spatial Information Sciences, Vol. XL3/W3. La Grande Motte, France, pp. 479-485.

Herman, L., Stachon, Z. (2016). Comparison of User Performance with Interactive and Static 3D Visualization Pilot Study. In: Halounova, L., et al. (eds.) ISPRS Archives of the Photogrammetry, Remote Sensing and Spatial Information Sciences, Vol. XLI-B2. Prague, Czech Republic, pp. 655-661.

Jankowski, J., Hulin, T., Hachet, M. (2014). A Study of Streetlevel Navigation Techniques in 3D Digital Cities on Mobile Touch Devices. In: IEEE 3DUI - Symposium on 3D User Interfaces. Minneapolis, United States. pp. 35-38.

Jokisch, M., Bartoschek, T., Schwering, A. (2011). Usability Testing of the Interaction of Novices with a Multi-touch Table in Semi Public Space. In: Jacko, J. A. (ed.) Human-Computer Interaction. Interaction Techniques and Environments, Lecture Notes in Computer Science, Berlin: Springer, pp. 71-80.

Konecny, M., Stanek. K. (2010). Adaptive cartography and geographical education. International Research in Geographical and Environmental Education, 19(1): 75-78.

Lienert, C., Jenny, B., Schnabel, O., Hurni, L. (2012). Current Trends in Vector-Based Internet Mapping: A Technical Review. In: Peterson, M. P. (ed.) Online Maps with APIs and Web Services, Springer, pp. 23-36.

Lin, H., Batty, M., Jørgensen, S., Fu, B., Konecny, M., Voinov, A., Torrens, P., Lu, G., Zhu, A., Wilson, J.P., Gong, J., Kolditz, O., Bandrova, T., Chen, M. (2015). Virtual Environments Begin to Embrace Process-based Geographic Analysis. Transactions In GIS, 19(4), pp. 493-498.

Lokka, I.-E., Coltekin, A. (2016). Simulating navigation with virtual 3D geovisualizations - A focus on memory related factors. In: Halounova, L., et al. (eds.) ISPRS Archives of the Photogrammetry, Remote Sensing and Spatial Information Sciences, Vol. XLI-B2. Prague, Czech Republic.

Marchal, D., Moerman, C., Casiez, G., Roussel, N. (2013). Designing Intuitive Multi-touch 3D Navigation Techniques. In: Kotze, p. et al. (eds.) Human-Computer Interaction INTERACT 2013. pp. 19-36.

Nurminen, A., Oulasvirta, A. (2008). Designing interactions for navigation in 3D mobile maps. In: L. Meng, A. Zipf, S. Winter (eds.), Map-based Mobile Services: Design, Interaction and Usability, Springer, London, UK. pp. 198-224. 
Popelka, S., Brychtova, A. (2013). Eye-tracking Study on Different Perception of 2D and 3D Terrain Visualization. Cartographic Journal. 50(3): 240-375.

Rönneberg, M., Sarjakoski T., Sarjakoski, L. T. (2014). Developing a Multi-Touch Map Application for a Large Screen in a Nature Centre. Nordic Journal of Surveying and Real Estate Research. 10(1): 47-62.

Sprinarova, K., Jurik, V., Sasinka, C., Herman, L., Sterba, Z., Stachon, Z., Chmelik, J., Kozlikova, B. (2015). Humancomputer Interaction in Real 3D and Pseudo-3D Cartographic Visualization: A Comparative Study. In: C. R. Sluter et al. (eds.) Cartography - Maps Connecting the World: 27th International Cartographic Conference 2015 - ICC2015, Switzerland: Springer International Publishing, pp. 59-73.

Svatonova, H., Rybansky, M. (2014). Visualization of landscape changes and threatening environmental processes using a digital landscape model. In: 8th International Symposium of the Digital Earth, ISDE 2014. IOP Conference Series: Earth and Environmental Science, Vol. 18, No. 1. Kuching, Sarawak, Malaysia.

Von Zadow, U., Daiber, F., Schőning, J., Krüger, A. (2011). GeoLens: Multi-User Interaction with Rich Geographic Information. In: Isenberg, P. et al. (eds.) Proceedings of the Workshop on Data Exploration for Interactive Surfaces DEXIS 2011. pp. 16-19.

Vozenilek, V. (2005). Cartography for GIS: Geovisualization and Map Communication. 1st ed., Palacký University Olomouc, $142 \mathrm{p}$.

White, J. (2009) Multi-touch interfaces and map navigation. Master thesis. University of Wisconsin-Madison, Madison.

Wilkening, J., Fabrikant, S. I. (2013). How users interact with a 3D geo-browser under time pressure. Cartography and Geographic Information Science. 40(1): 40-52.

Wood, J., Kirschenbauer, S., Döllner, J., Lopes, A., Bodum, L. (2005). Using 3D in Visualization. In: Dykes, J., MacEachren, A. M., Kraak, M.-J. (eds.) Exploring Geovisualization. Elsevier, Amsterdam, pp. 295-312.

Zhang, S., Moore, A. B. (2013). The Usability of Online Geographic Virtual Reality for Urban Planning. In Isikdag, U. (ed.) ISPRS Archives of the Photogrammetry, Remote Sensing and Spatial Information Sciences, Vol. XL-2/W2, Istanbul, Turkey. pp. 145-150. 
APPENDIX

\begin{tabular}{|c|c|c|c|c|c|c|c|c|}
\hline \multirow[b]{2}{*}{$\begin{array}{l}\text { device }(\mathrm{OS}, \\
\text { version) }\end{array}$} & \multirow[b]{2}{*}{$\begin{array}{c}\text { web } \\
\text { browser }\end{array}$} & \multirow[b]{2}{*}{ library } & \multicolumn{6}{|c|}{ gesture } \\
\hline & & & tap & $\begin{array}{c}\text { double } \\
\text { tap }\end{array}$ & press & pan & rotate & $\begin{array}{c}\text { pinch / } \\
\text { zoom }\end{array}$ \\
\hline \multirow{10}{*}{$\begin{array}{l}\text { Smartphone Leagoo } \\
\text { Elite } 5 \text { Android } 5.1\end{array}$} & \multirow{5}{*}{$\begin{array}{c}\text { Google } \\
\text { Chrome 50.0 }\end{array}$} & SceneJS & & III. & I. & I. & I., III. & III. \\
\hline & & Three.js & & & & I. & III. & III. \\
\hline & & XML3D & & & & I. & I., II., III. & III. \\
\hline & & X3DOM & & III. & & I. & III. & III. \\
\hline & & SpiderGL & & & & & & \\
\hline & \multirow{5}{*}{ Opera 36.2} & SceneJS & & III. & & I. & III. & III. \\
\hline & & Three.js & & & & I. & III. & III. \\
\hline & & XML3D & & & & I. & I., II., III. & III. \\
\hline & & X3DOM & & III. & & I. & III. & III. \\
\hline & & SpiderGL & & & & & & \\
\hline \multirow{5}{*}{$\begin{array}{l}\text { Smartphone Lenovo } \\
\text { S750, Android } 4.2\end{array}$} & \multirow{5}{*}{$\begin{array}{c}\text { Mozilla } \\
\text { Firefox } 34.0\end{array}$} & SceneJS & \multicolumn{6}{|c|}{ Web browser crashes after loading 3D model } \\
\hline & & Three.js & \multicolumn{6}{|c|}{ Web browser crashes after loading 3D model } \\
\hline & & XML3D & & & & I. & III. & III. \\
\hline & & X3DOM & & & & I. & & \\
\hline & & SpiderGL & & & & & & \\
\hline \multirow{5}{*}{$\begin{array}{l}\text { Tablet Fujitsu, } \\
\text { Android 4.1.1 }\end{array}$} & \multirow{5}{*}{$\begin{array}{c}\text { Mozilla } \\
\text { Firefox } 48.0\end{array}$} & SceneJS & \multicolumn{6}{|c|}{ Web browser crashes after loading 3D model } \\
\hline & & Three.js & \multicolumn{6}{|c|}{ Web browser crashes after loading 3D model } \\
\hline & & XML3D & & & & I. & II., III. & III. \\
\hline & & X3DOM & \multicolumn{6}{|c|}{ Web browser crashes after loading 3D model } \\
\hline & & SpiderGL & \multicolumn{6}{|c|}{ Web browser crashes after loading 3D model } \\
\hline \multirow{5}{*}{$\begin{array}{l}\text { Tablet Databox, } \\
\text { Windows } 10 \text { Home }\end{array}$} & \multirow{5}{*}{$\begin{array}{l}\text { Microsoft } \\
\text { Edge } 20\end{array}$} & SceneJS & & & & & & \\
\hline & & Three.js & & & & & & \\
\hline & & XML3D & & & & & & \\
\hline & & X3DOM & I., II., III. & & & I. & & \\
\hline & & SpiderGL & & & & & & \\
\hline \multirow{5}{*}{$\begin{array}{l}\text { Notebook Dell with } \\
\text { touch screen Acer, } \\
\text { Windows } 10\end{array}$} & \multirow{5}{*}{$\begin{array}{c}\text { Google } \\
\text { Chrome } 51.0\end{array}$} & SceneJS & & & & I. & III. & III. \\
\hline & & Three.js & & & & I. & III. & III. \\
\hline & & XML3D & & & & I. & III. & III. \\
\hline & & X3DOM & & IV. & & I. & I. & III. \\
\hline & & SpiderGL & & & & & & \\
\hline \multirow{5}{*}{$\begin{array}{l}\text { Desktop with touch } \\
\text { screen Acer, } \\
\text { Windows } 8.1 \text { Pro }\end{array}$} & \multirow{5}{*}{$\begin{array}{c}\text { Mozilla } \\
\text { Firefox } 47.0\end{array}$} & SceneJS & & & & I. & III. & III. \\
\hline & & Three.js & & & II. & I. & III. & III. \\
\hline & & XML3D & & & III. & I. & III. & III. \\
\hline & & X3DOM & & IV. & III. & I. & III. & III. \\
\hline & & SpiderGL & & & & & & \\
\hline $\begin{array}{l}\text { rot: } \\
\text { mo }\end{array}$ & $n$ of 3D & shift of 3I & odel III. & $\begin{array}{l}\text { zoom in / } \\
\text { out }\end{array}$ & & $\begin{array}{l}\text { set } \\
\text { rot: }\end{array}$ & $\begin{array}{l}\text { nter of } \\
\text { on }\end{array}$ & \\
\hline
\end{tabular}

